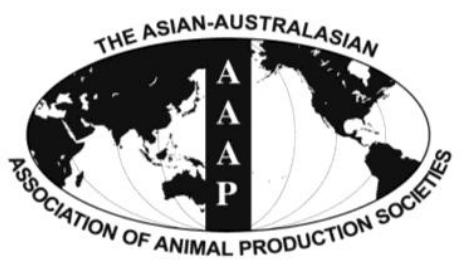

Asian-Aust. J. Anim. Sci.

Vol. 25, No. 12 : 1721-1725 December 2012

http://dx.doi.org/10.5713/ajas.2012.12395

www.ajas.info

pISSN 1011-2367 elSSN 1976-5517

\title{
Growth and Nutrient Utilization in Kids Fed Expander-extruded Complete Feed Pellets Containing Red Gram (Cajanus cajan) Straw
}

\author{
P. B. Reddy*, T. J. Reddy and Y. R. Reddy \\ Animal Nutrition Department, College of Veterinary Science, S.V. Veterinary University, Hyderabad, -500 030, India
}

\begin{abstract}
A growth and digestibility study was conducted using Osmanabadi goat male kids by feeding complete diets in the form of mash or expander extruded pellets containing different levels of red gram (Cajanus cajan) straw (RGS). Two iso-nitrogenous complete diets were prepared by incorporating RGS at 35\% and 50\% levels. Half the quantity of each complete mash feed was then converted into pellets through expander extruder processing. Thirty two kids of 4 to 5 months age were divided into four groups of eight each and were fed for $150 \mathrm{~d}$ with four experimental diets (T1: mash with 35\% RGS, T2: mash with 50\% RGS, T3: pellets with 35\% RGS and T4: pellets with 50\% RGS). Pelleting of complete diets significantly $(\mathrm{p}<0.001)$ increased the voluntary feed intake $(671.45 \mathrm{vs}$ $426.28 \mathrm{~g} / \mathrm{d}$ ) at both levels of RGS in the feeds. Average daily gain (ADG, g/d) also increased significantly ( $\mathrm{p}<0.001)$ from 48.79 in kids fed mash diet to 71.29 in those fed with pelleted diets. Feed conversion efficiency (dry matter (DM) intake: weight gain) was comparable among all the treatment groups. Digestibility of nutrients was not affected by pelleting of the feeds whereas, increasing the level of inclusion of RGS in feeds from $35 \%$ to $50 \%$ decreased ( $\mathrm{p}<0.05)$ the digestibility of DM and crude protein $(\mathrm{CP})$ resulting in lower $(\mathrm{p}<0.001)$ metabolizable energy $(\mathrm{ME})$ content $(\mathrm{MJ} / \mathrm{kg} \mathrm{DM})$ in feeds with $50 \%$ RGS $(7.93 \mathrm{vs} 8.75)$. Daily intake $\left(\mathrm{MJ} / \mathrm{kg} \mathrm{BW}^{-0.75}\right)$ of ME decreased $(\mathrm{p}<0.05)$ in feeds containing 50\% RGS while pelleting of feeds increased $(\mathrm{p}<0.05)$ the intake of DM, CP, digestible crude protein (DCP) and ME. It is inferred that expander extruder pelleting can efficiently utilize RGS up to 50\% level in complete diets for growing goat kids. (Key Words: Goat, Feed Processing, Red Gram (Cajanus cajan) Straw, Expander Extruder Pelleting, Complete Diets)
\end{abstract}

\section{INTRODUCTION}

Availability of feed and fodder, both in quantitative and qualitative terms, is one of the major constraints in sustainable development of the livestock sector. It is well recognized that effective utilization of crop residues as animal feed is an alternative to overcome feed shortages for ruminant feeding (Rangnekar, 2003). Poor palatability and low bulk density apart from low nutritive value are restricting the utilization of the crop residues as animal feeds. Since the mid 1980's there has been much research and development into finding ways of alleviating these short comings (Sundstol and Owen, 1984; Doyle et al., 1986). Incorporation of crop residues as a roughage source in complete diets (total mixed rations) of ruminants and their further densification is one of the practical ways of

\footnotetext{
* Corresponding Author: P. Baswa Reddy. National Research Centre on Meat, Chengicherla, Uppal P.B.No:19, Hyderabad500039, India. Tel: +914027204541, Fax: +914027201672, E-mail: baswareddy@gmail.com

Submitted Jul. 17, 2012; Accepted Sept. 14, 2012; Revised Sept. 24, 2012
}

their utilization. Pelleting of low grade roughage based feeds improves uniformity, increases density, facilitates ease of handling and reduces wastage (Stevens, 1981). Similarly, physical form of the diet can affect potential rate of consumption with pelletized diets ingested more rapidly than the ones in mash form (Fahey et al., 1993; Berger et al., 1994). Though the argument on ill effect of goat rearing on ecology is a debatable issue, it is widely felt that unrestricted movement of goats should be prevented and goats with high production potential, which are capable of responding to quality feed, should be reared under confinement. Red gram (pigeon pea, Cajanus cajan) is a major pulse crop grown in Telangana region of Andhra Pradesh state in India. The straw that remains after harvesting the crop is regarded as wasteful product and is generally burnt out in the fields. Though red gram straw like many other agro industrial by-products is not palatable to animals in its original form, the nutrients present in the straw can potentially be made available to animals after applying suitable processing methods (Salem and Smith, 2008). Few efforts have been made to utilize red gram straw 
in the diets of different ruminant species (Narayanaswamy et al., 1990; Reddy, 1997; Suresha et al., 2006). An attempt has been made in the present study to utilize red gram straw (RGS) by incorporating into complete diets and feeding to goats in the form of mash or expander extruder processed pellets to assess growth and nutrient utilization under stall fed conditions.

\section{MATERIALS AND METHODS}

\section{Animals and diets}

Two iso-nitrogenous complete mash feeds were prepared by incorporating red gram (Cajanus cajan) straw at 35 and $50 \%$ level maintaining the total roughage content in both the rations at $60 \%$ level. The remaining component of the forage portion comprised of lucaena leaves (Table 1). For preparation of complete feeds in mash form, all the ingredients including roughages were ground in a chopper cum grinder hammer mill using $8 \mathrm{~mm}$ sieve. The ground material along with molasses, mineral mixture, salt and vitamin premix was mixed together in a horizontal batch mixer to attain uniform blending of all the ingredients. Half the quantity of each mash feed was then converted into pellets through expander-extrusion processing. For preparation of pellets, the mash with 12 to $13 \%$ moisture at room temperature was reconstituted with water to yield 17 to $18 \%$ moisture and the reconstituted mash was sent from mixer into the hopper above the expander-extruder from which it passed through the screw in which it attained 90 to $92^{\circ} \mathrm{C}$ by the time it came out of the die openings in the form

Table 1. Ingredient and chemical composition of complete diets

\begin{tabular}{lrc}
\hline Component & CF 35 & CF 50 \\
\hline Ingredient composition (\%) & & \\
$\quad$ Red gram straw* & 35 & 50 \\
Dried lucaena leaves & 25 & 10 \\
Ground nut cake & 5 & 8 \\
Maize & 30 & 14 \\
Wheat bran & 0 & 5 \\
Red gram husk & 0 & 8 \\
Molasses & 2 & 2 \\
Mineral and vitamin mixture ${ }^{1}$ & 2 & 2 \\
Salt & 1 & 1 \\
Chemical composition (g/kg DM) & & \\
Crude protein & 120.6 & 123.4 \\
Crude fibre & 213.4 & 265.2 \\
Ether extract & 29.5 & 26.2 \\
Total ash & 107.5 & 108.6 \\
Calcium & 13.1 & 12.6 \\
Phosphorus & 7.7 & 7.0 \\
ME (MJ/kg DM, calculated) & 9.4 & 8.6 \\
\hline${ }^{1}$ Vitamin mixture (Rovimix) added at 20 g per 100 kg. \\
* Red gram straw contained 9.26\% CP, 42.44\% CF, 1.24\% EE, 38.64\% \\
NFE, 8.42\% TA, 1.06\% Ca, 0.23\% P. & & \\
& &
\end{tabular}

of pellets (Valadez, 2008). Thirty-two weaned male kids of Osmanabadi breed in the age group of 4 to 5 months were divided into four groups of eight animals each and were kept as four groups in well ventilated pens. Care has been taken to have similar average body weights in all the four groups. The experimental feeds $\left(\mathrm{T}_{1}\right.$ : mash with $35 \%$ RGS, $\mathrm{T}_{2}$ : mash with $50 \%$ RGS, $\mathrm{T}_{3}$ : pellets with $35 \%$ RGS and $\mathrm{T}_{4}$ : pellets with $50 \%$ RGS) were randomly assigned to the four treatment groups and the animals in respective groups were offered those feeds for $150 \mathrm{~d}$. Clean drinking water in troughs was kept available ad libitum to the animals all the time. Water in the troughs was changed twice daily. All the animals were dewormed at the beginning of the experiment and once again in the middle of the experiment after two and half months. They were vaccinated against Hemorrhagic Septicemia and Enterotoxaemia.

\section{Experimental procedure}

Animals in each group were offered weighed quantities of respective rations ad libitum at 0900 and $1600 \mathrm{~h}$ daily. In order to ascertain ad libitum feed consumption, daily feed offered was maintained at 110 per cent of previous day's consumption. The left over residues were weighed on the next day morning to arrive at daily feed consumption. The animals were weighed at fortnightly intervals consecutively for three days in the morning before feed or water was offered.

A digestion trial was conducted at the end of the growth experiment to assess nutrient digestibilities of the four experimental feeds. The animals were kept in wellventilated hygienic individual metabolism cages with feeding and watering arrangements. Each cage was provided with a feed trough and a water trough. Measured quantity of feed was offered each day and the left over feed was measured the next day morning to arrive at the daily feed consumption. Clean drinking water in a water trough was kept available ad libitum to the animals throughout the period. A preliminary period of seven days was allowed for the animals to get acclimatized to the cage environment followed by seven days of collection period. During the collection period, daily feed consumption and faeces voided were measured for each animal and the representative samples of feed and faeces were dried in a hot air oven to estimate the dry matter and pooled for seven days for further analysis. 1/100th part each of the fresh faeces voided daily by individual animal was preserved in diluted sulphuric acid for nitrogen estimation.

\section{Analytical methods}

Feed and faecal samples were analyzed for proximate principles as per the procedures of AOAC (1995). Metabolizable energy (ME) values were calculated from TDN as per NRC (1981) formula. The effects of feed 
processing (mash vs pellet) and level of red gram straw (35\% vs 50\%) in complete diets on feed intake, growth and nutrient utilization were analyzed using general linear model procedure of Statistical Package for Social Sciences (SPSS) (1996) in a $2 \times 2$ factorial arrangement.

\section{RESULTS}

On dry basis, red gram straw contained $9.26 \%$ crude protein (CP), $42.44 \% \mathrm{CF}, 1.24 \% \mathrm{EE}, 8.42 \%$ ash, $1.06 \%$ calcium and $0.23 \%$ phosphorus. The average daily feed intake during growth period was significantly $(\mathrm{p}<0.001)$ higher on pelleted diets while the effect of level of RGS in the diets on intake was non significant (Table 2). Goats consumed an average of 671.45 and $426.28 \mathrm{~g}$ feed on pelleted and mash diets respectively irrespective of level of RGS. The intake was 552.38 and $545.36 \mathrm{~g} / \mathrm{animal} / \mathrm{d}$ on feeds containing 35 and 50\% RGS respectively irrespective of method of processing. Total weight gain and average daily gain $(A D G)$ in kids were also significantly $(p<0.001)$ influenced by feed processing while the effect of level of inclusion of RGS was non significant on growth rate. Goats on pelleted feeds gained an average of $10.69 \mathrm{~kg}$ in $150 \mathrm{~d}$ with an ADG of $71.29 \mathrm{~g}$ whereas those on mash feed gained only $48.79 \mathrm{~g}$ per day irrespective of level of RGS. The total weight gain $(\mathrm{kg})$ and $\mathrm{ADG}(\mathrm{g})$ on feeds with $35 \% \mathrm{RGS}$ were 9.48 and 63.17 while those on feeds with $50 \%$ RGS were 8.54 and 56.92 respectively. Apparent digestibility of nutrients was similar among mash and pelleted feeds (Table 2). Increasing the RGS in feeds decreased the digestibility of dry matter (DM), CP and CF resulting in lower $(\mathrm{p}<0.001)$ ME content in feeds containing 50\% RGS. Though nutritive value of feeds was not affected due to pelleting, the average daily intake of DM, CP, digestible crude protein (DCP) and metabolizable energy (ME) per unit metabolic body weight were significantly $(\mathrm{p}<0.01)$ higher in pelleted diets. The Feed conversion efficiency (DMI:wt gain) was comparable among all the treatment groups.

\section{DISCUSSION}

Red gram straw used in the present study contained slightly lower $\mathrm{CP}$ and $\mathrm{EE}$ and higher $\mathrm{CF}$ and total ash contents when compared to the reports of Raut et al. (2002) and Rekhate et al. (2007) whereas, Kishore et al. (1997) reported slightly lower $\mathrm{CP}$ and $\mathrm{CF}$ and higher $\mathrm{EE}$ and total ash contents in red gram straw. Varietal differences among red gram crops might be the reason for this variation in proximate composition of straw. During the preparation of pellets, the procedure of reconstitution with water was followed instead of directly adding steam to the feed while passing through the screw to simplify the procedure for small scale production with minimal power consumption under field conditions wherein it may not always be possible to maintain boilers for steam generation (Valadez, 2008). The significantly $(\mathrm{p}<0.001)$ higher feed intake on pelleted diets might be due to the soft, pliable and cooked nature of expander extruded pellets together with natural disinclination of goats towards fineness of feed. The increase in intake due to pelleting of complete diets was in

Table 2. Weight gain, voluntary feed intake, nutrient digestibility and nutrient intake by goats on experimental feeds

\begin{tabular}{|c|c|c|c|c|c|c|c|c|}
\hline & \multicolumn{2}{|c|}{ Mash } & \multicolumn{2}{|c|}{ Pellet } & \multirow{2}{*}{$\begin{array}{c}\text { Pooled } \\
\text { SE }\end{array}$} & \multicolumn{3}{|c|}{ Significance (p-value) } \\
\hline & $\begin{array}{l}35 \% \\
\text { RGS }\end{array}$ & $\begin{array}{l}50 \% \\
\text { RGS }\end{array}$ & $\begin{array}{l}35 \% \\
\text { RGS }\end{array}$ & $\begin{array}{l}50 \% \\
\text { RGS }\end{array}$ & & $\begin{array}{c}\text { Feed } \\
\text { processing (FP) }\end{array}$ & $\begin{array}{l}\text { Straw level } \\
\text { (S) }\end{array}$ & $\mathrm{FP} \times \mathrm{S}$ \\
\hline Initial weight $(\mathrm{kg})$ & 11.03 & 11.05 & 11.04 & 11.04 & 0.27 & 1.000 & 0.983 & - \\
\hline Final weight $(\mathrm{kg})$ & 19.00 & 17.71 & 22.01 & 21.45 & 0.64 & 0.008 & 0.439 & 0.761 \\
\hline $\mathrm{ADG}(\mathrm{g} / \mathrm{d})$ & 53.17 & 44.12 & 73.17 & 69.42 & 3.23 & $<0.001$ & 0.234 & 0.631 \\
\hline Voluntary feed intake $(\mathrm{g} / \mathrm{d})$ & 432.06 & 420.50 & 672.69 & 670.21 & 23.94 & $<0.001$ & 0.724 & 0.819 \\
\hline DMI to gain ratio & 8.39 & 9.41 & 8.64 & 9.24 & 0.37 & 0.959 & 0.299 & 0.786 \\
\hline \multicolumn{9}{|l|}{ Apparent digestibility (\%) } \\
\hline $\mathrm{DM}$ & 60.25 & 57.86 & 59.73 & 56.52 & 0.68 & 0.466 & 0.043 & 0.745 \\
\hline $\mathrm{CP}$ & 72.41 & 70.34 & 71.28 & 69.34 & 0.49 & 0.248 & 0.040 & 0.939 \\
\hline $\mathrm{CF}$ & 49.27 & 44.33 & 45.53 & 45.39 & 0.76 & 0.329 & 0.078 & 0.093 \\
\hline $\mathrm{EE}$ & 85.54 & 83.20 & 83.35 & 83.09 & 0.47 & 0.206 & 0.158 & 0.254 \\
\hline \multicolumn{9}{|l|}{ Nutritive value } \\
\hline $\mathrm{DCP}(\%)$ & 8.73 & 8.68 & 8.60 & 8.56 & 0.05 & 0.248 & 0.665 & 0.945 \\
\hline $\operatorname{ME}(\mathrm{M} \mathrm{J} / \mathrm{kg} \mathrm{DM})$ & 8.89 & 7.97 & 8.61 & 7.90 & 0.12 & 0.203 & $<0.001$ & 0.432 \\
\hline \multicolumn{9}{|c|}{ Nutrient intake per kg BW ${ }^{-0.75}$} \\
\hline $\mathrm{DM}(\mathrm{g})$ & 66.54 & 65.82 & 77.47 & 77.56 & 2.16 & 0.008 & 0.932 & 0.912 \\
\hline $\mathrm{CP}(\mathrm{g})$ & 8.03 & 8.13 & 9.34 & 9.57 & 0.26 & 0.008 & 0.709 & 0.883 \\
\hline $\mathrm{DCP}(\mathrm{g})$ & 5.81 & 5.72 & 6.65 & 6.62 & 0.17 & 0.010 & 0.830 & 0.911 \\
\hline $\mathrm{ME}(\mathrm{MJ})$ & 0.59 & 0.52 & 0.66 & 0.61 & 0.017 & 0.011 & 0.044 & 0.830 \\
\hline
\end{tabular}


agreement with the reports of Singhal and Mudgal (1983), Reddy and Reddy (1991a) and Reddy et al. (1992). Hale and Theurer (1972) opined that pelleting of feeds increases acceptability by animals. Pi et al. (2005) reported higher feed intake in goats due to pelletization of complete diets. Gipson et al. (2007) offered alfalfa based complete feeds in pelleted as well as mash forms under stall feeding to meat goats and found significantly higher DM intake on pelleted diets. Similar total roughage level rather than the level of RGS in the diets might be the reason for similarity in intake between complete diets containing 35\% and 50\% RGS. The average daily gain observed in kids on mash feed was comparable with the reports of Murthy et al. (1995) who observed an ADG of $44.6 \mathrm{~g}$ and Chandrasekharaiah et al. (1996) who reported an ADG of 44.7 to $53.4 \mathrm{~g}$ when feed was offered in mash form. The higher weight gains on pelleted feeds were in agreement with the findings of Raut et al. (2002) wherein an ADG of $75 \mathrm{~g}$ was reported when complete diets containing $60 \%$ roughage were offered in pelleted form. The similarity in digestibility of nutrients between pelleted and mash diets was in contrast to the reports of Singhal and Mudgal (1983) who reported slight decrease and Reddy and Reddy (1991b) who reported an increase in digestibility of nutrients due to pelletization of complete diets. The decrease $(p<0.05)$ in digestibility of $\mathrm{DM}$ and $\mathrm{CP}$ in diets containing 50\% RGS was in agreement with the findings of Reddy and Raghavan (1987) and Reddy and Reddy (1984) who also reported a decrease in the digestibility of these nutrients due to an increase of roughage and fiber contents in feeds. The similarity in feed conversion efficiency (DMI: wt gain) among all the treatment groups indicated that the higher weight gain attained on pelleted dies was due to higher feed intake rather than higher nutritive value.

\section{CONCLUSIONS}

Expander extruder pelleting of complete diets significantly increased the voluntary feed intake and weight gain in goats and enabled effective utilization of red gram straw up to $50 \%$ level in complete diets.

\section{ACKNOWLEDGEMENTS}

The authors are grateful to Indian Council of Agricultural Research for providing financial support to carry out the work under the World Bank aided NATP (RPPS-12) project.

\section{REFERENCES}

AOAC. 1995. Official methods of analysis (16th Ed). Association of Official Analytical Chemists. Washington DC, USA.
Ben Salem, H. and T. Smith. 2008. Feeding strategies to increase small ruminant production in dry environments. Small Rumin. Res. 77:174-194.

Berger, L. L., G. C. Fahey Jr., L. D. Bourquin and E. C. Titgemeyer. 1994. Modification of forage quality after harvest. In: Forage quality, Evaluation, and Utilization (Ed. G. C.Fahey Jr.). ASA-CSSA-SSSA, Madison, WI, 922-966.

Chandrasekharaiah, M., M. R. Reddy and G. V. N. Reddy. 1996. Effect of feeding urea treated maize stoer on growth and nutrient utilization by sheep and goats. Small Rumin. Res. 22: 141-147.

Doyle, P. T., C. Devendra and G. R. Pearce. 1986. Rice Straw as a Feed for Ruminants. International Programme of Australian Universities and Colleges Ltd. (IDP), Canberra

Fahey, G. C., L. D. Bourquin, E. C. Titgemeyer and D. G. Atwel. 1993. Post harvest treatment of fibrous feedstuffs to improve their nutritive value. In: Forage cell wall structure and digestibility (Ed. H. G. Jung, D. R. Buxton, R. D. Hatfield and J. Ralph). ASA-CSSA-SSSA, Madison, WI, 715-766.

Gipson, T. A., A. L. Goetsch, G. Detweiler and T. Sahlu. 2007. Effects of feeding method, diet nutritive value and physical form and genotype on feed intake, feeding behavior and growth performance by meat goats. Small Rumin. Res. 71: 170-178.

Hale, W. H. and C. B. Theurer. 1972. Feed preparation and processing. In: Digestive physiology and nutrition of ruminants (Ed. D. C. Church). Vol.3. Dept.Animal Science, Oregon State University, Corvallis, OR, USA, pp. 49-76.

Kishore, A., Prakash Chandra and J. L. Ogra. 1997. Phenotypic traits of gain in kids on buffers included diets. Indian J. Dairy Sci. 50:448-451.

Murthy, K. S., M. R. Reddy and G. V. N. Reddy. 1995. Utilization of cage layer droppings and poultry litter as feed supplements for lambs and kids. Small Rumin. Res. 16:221-225.

Narayanaswamy, P., M. Parthasarathy and N. Krishna. 1990. Evaluation of complete rations containing groundnut haulms, banyan (Ficus bengalensis) tree leaves and red gram straw in sheep. Indian J. Anim. Nutr. 7:127-130.

NRC. 1981. Nutrient requirements of goats. National Academy of Sciences, National Research Council. Washington, DC, USA.

Pi, Z. K., Y. M. Wu and J. X. Liu. 2005. Effect of pre treatment and pelletization on nutritive value of rice straw - based total mixed ration,and growth performance and meat quality of growing boer goats fed on TMR. Small Rumin. Res. 56:81-88.

Rangnekar, D. V. 2003. Future strategies of livestock feed technologies to meet challenges. In: Feed Technology-Present status and future strategies. Proceedings of workshop held at ANGR Agricultural University, Hyderabad, India. 22-23 July, 2003.

Raut, R. G., D. H. Rekhate and A. P. Dhok. 2002. In vitro evaluation of Arhar (Cajanus cajan) straw based pelleted complete feed and dry matter intakes in goats. Indian J. Small Rumin. 8:23-26.

Reddy, D. V. 1997. The effect of supplementation of legume straws on utilization of rice straw-poultry droppings-rice branfishmeal based diet in buffaloes. Anim. Feed Sci. Technol. 69: 305-314.

Reddy, G. V. N. and M. R. Reddy. 1984. Dry fallen mango tree leaves as roughage source in complete feeds for sheep. Indian 
J. Anim. Sci. 54:1046-1050.

Reddy, G. V. N. and M. R. Reddy. 1991a. Effect of processing groundnut hulls on nutrient utilization in sheep and goats. Indian J. Anim. Nutr. 8:123-126.

Reddy, G. V. N. and M. R. Reddy. 1991b. Effect of processing of Sehima nervosum dry grass on nutrient utilization in sheep and goats. Indian J. Anim. Nutr. 8:27-34.

Reddy, M. R., T. Govindaiah and G. V. N. Reddy. 1992. Effect of physical processing on nutritive value of cotton straw in goats and sheep. Indian J. Anim. Nutr. 9:141-145

Reddy, T. J. and G. V. Raghavan. 1987. Studies on feeding different planes of nutrition on utilization of nutrients by intensively fed indigenous goats. Indian Vet. J. 64:505-510.

Rekhate, D. H., V. B. Madavi and A. P. Dhok. 2007. Performance of goats fed Arhar (Cajanus cajan) straw based pelleted complete ration. Anim. Nutr. Feed Technol. 7:47-52.
Singhal, K. K. and V. D. Mudgal. 1983. Utilization of complete feed by goats. Indian J. Dairy Sci. 36:250-254.

SPSS. 1996. Statistical Package for Social Sciences, Version 7.5, SPSS inc., Illinois, USA.

Stevens, C. 1981. Pelleting: Emphasis on by products and roughage ingredients. Feedstuffs, 53: $\mathrm{E}_{1}-\mathrm{E}_{3}$.

Sundstol, F. and E. Owen. (editors) 1984. Straw and other fibrous by-products as feed. Elsevier, Amsterdam.

Suresha, C., B. Ramachandra, B. Suresh, N. Prasad, C. B. Madhav and V. B. Shetter. 2009. Evaluation of red gram and bengal gram based pelleted complete diets in goats. Indian J. Anim. Nutr. 26:349-353.

Valadez, M. G., G. M. Hernandez and R. S. Lopez. 2008. Design and evaluation of an extruder to convert crop residues to animal feed. Biosyst. Eng. 100:66-78. 